\title{
Generation of Recombinant Antibodies against the beta-(1,6)-Branched beta-(1,3)-D-Glucan Schizophyllan from Immunized Mice via Phage Display
}

\author{
Jörn Josewski, ${ }^{1}$ Sabine Buchmeier, ${ }^{2}$ André Frenzel, ${ }^{1,3}$ Philip Tinnefeld, ${ }^{2}$ \\ Stefan Dübel, ${ }^{1}$ and Udo Rau' ${ }^{1}$ \\ ${ }^{1}$ Department for Biotechnology, Institute of Biochemistry, Biotechnology and Bioinformatics, Technische Universität Braunschweig, \\ Spielmannstraße 17, 38106 Braunschweig, Germany \\ ${ }^{2}$ Institute for Physical and Theoretical Chemistry, Technische Universität Braunschweig, Rebenring 56, 38106 Braunschweig, Germany \\ ${ }^{3}$ YUMAB GmbH, Rebenring 33, 38106 Braunschweig, Germany
}

Correspondence should be addressed to Udo Rau; u.rau@tu-bs.de

Received 28 February 2017; Accepted 2 May 2017; Published 23 May 2017

Academic Editor: Maxim Golovkin

Copyright (C) 2017 Jörn Josewski et al. This is an open access article distributed under the Creative Commons Attribution License, which permits unrestricted use, distribution, and reproduction in any medium, provided the original work is properly cited.

\begin{abstract}
beta-(1,6)-Branched beta-(1,3)-D-glucans like schizophyllan from the basidiomycete Schizophyllum commune excite various immunostimulatory effects and have been clinically tested as adjuvants. Some of the glucans are also applicable in food or petrol industry due to their viscosity and temperature stability in aqueous solution. Antibodies against these glucans could be used as tool for analysis of glucan preparations or for further research of its bioactivity. Therefore, an immune phage display library was constructed from mice immunized with schizophyllan. Three recombinant monoclonal antibodies were isolated from this library by affinity selection (panning) on schizophyllan. The half-maximal effective concentration (EC50) values for those antibodies varied between $16.4 \mathrm{ng} \mathrm{mL}^{-1}$ and $21.3 \mathrm{ng} \mathrm{mL}^{-1}$. The clones showed binding specificity not only for schizophyllan but also for other beta(1,6)-branched beta-(1,3)-D-glucans of similar macromolecular structure. Denaturation of the secondary structure led to a reduced antibody binding, indicating an epitope requiring the correct conformation of the triple helical structure of the glucans.
\end{abstract}

\section{Introduction}

A variety of fungal beta-(1,3)-D-glucans are described as substances with antitumoral and immunomodulating activities [1]. One example is schizophyllan (SCH) that is produced as extracellular polysaccharide by the basidiomycete Schizophyllum commune [2-5]. Its bioactivity is based on the enhancement of cell-mediated immune response with stimulation of $\mathrm{T}$ lymphocytes and macrophages and improving cytokine production [6-9].

The primary molecular structure of $\mathrm{SCH}$ consists of a beta-(1,3)-D-glucan main chain with single beta-(1,6)-linked glucose molecules at approximately every third glucose monomer of the backbone [10, 11]. In aqueous solution it forms the secondary structure of a triplex composed of three twisted chains stabilized by hydrogen bonds with single beta-(1,6)-linked glucose residues protruding outside the helix backbone [12-15]. Differences in branching grade and molecular weight are considered to be responsible for variations in bioactivity [16-18]. In addition to its bioactivity, $\mathrm{SCH}$ also has physical properties favorable for a use in food and oil industry. Aqueous solutions of SCH are viscous and show pseudoplastic flow behavior [19]. Furthermore, they are stable at high temperature and in a broad $\mathrm{pH}$ range, starting to denature at $\mathrm{pH}>12$ or $>135^{\circ} \mathrm{C}[15,20,21]$. Since $\mathrm{SCH}$ can be used for many applications, the generation of antibodies would be of great value because they could be used for quantitative trace analysis or for the investigation of the role of particular conformations for glucan bioactivity.

The objective of this study was the generation of recombinant monoclonal antibodies (rAbs) against the beta- $\mathrm{D}$ glucan schizophyllan. Therefore, we constructed an antibody phage display library from the lymphocytes of three mice which had been immunized with proteinase $\mathrm{K}$ treated $\mathrm{SCH}$ 
(SCH-PK). After panning of this library for SCH-PK binding antibody phage, we were able to derive three $\mathrm{rAbs}$ specificity binding beta-(1,6)-branched beta-(1,3)-D-glucans with the same secondary structure as $\mathrm{SCH}$.

\section{Materials and Methods}

2.1. Chemicals. All chemicals were purchased from Sigma Aldrich if not mentioned otherwise.

2.2. Preparation of beta-(1,6)-Branched beta-(1,3)-D-Glucans. Following beta-(1,6)-branched beta- $(1,3)$-D-glucans were prepared from biomass-free and stabilized $\left(5 \mathrm{gL}^{-1}\right.$ formic acid) culture supernatants: SCH (Schizophyllum commune ATCC 38548), scleroglucan (Sclerotium rolfsii ATCC 15205), cinerean (Botrytis cinerea LU 14548), and fructican (Monilinia fructigena ATCC 24976) [4, 22-24]. The supernatants were diluted to $1.0 \mathrm{~g} \mathrm{~L}^{-1}$ glucan (volume $100 \mathrm{~mL}$ ) with water and adjusted to $\mathrm{pH} 7.5$ with $\mathrm{NaOH}$. In the next step the glucan solutions were purified by diafiltration with water (Vivaflow 50 R, MWCO 100,000, Sartorius, Göttingen, Germany) until the conductance of the retentate dropped to $0 \mu \mathrm{S} \mathrm{cm}^{-1}$. The glucan solution was then reduced to $100 \mathrm{~mL}$ and sterilized at $120^{\circ} \mathrm{C}$ for 20 minutes. Quantification was performed by mixing of $5 \mathrm{~mL}$ glucan solution with $15 \mathrm{~mL}$ 2-propanol and incubation overnight at $4^{\circ} \mathrm{C}$. The precipitated glucan was weighed after isolation by centrifugation with $13,000 \times \mathrm{g}$ at $4^{\circ} \mathrm{C}$ as well as drying for $48 \mathrm{~h}$ at $50^{\circ} \mathrm{C}$ under reduced pressure.

In addition to this schizophyllan preparation, commercially acquired samples of schizophyllan from Contipro Biotech (Dolní Dobrouč, Czech Republik) and Actigum ${ }^{\mathrm{TM}}$ CS 11 (scleroglucan) purchased from Degussa Construction Polymers GmbH (Trostberg, Germany) were used.

2.3. Preparation of Proteinase K Treated Glucans. SCH additionally treated with proteinase $\mathrm{K}$ ( $\mathrm{SCH}-\mathrm{PK})$ was used as antigen for the isolation of antibodies. For its preparation, biomass-free culture supernatant of $S$. commune was diluted to $1.0 \mathrm{~g} \mathrm{~L}^{-1}$ glucan in $100 \mathrm{~mL}$ with water and adjusted to $\mathrm{pH} 7.5$ with $\mathrm{NaOH}$. $2 \mathrm{~mL}$ of $0.5 \mathrm{~mol} \mathrm{~L}^{-1} \mathrm{CaCl}_{2}$ in $1 \mathrm{~mol} \mathrm{~L}^{-1}$ Tris- $\mathrm{HCl}$ ( $\mathrm{pH} 7.4$ ) and $1 \mathrm{~mL}$ of $10 \%(\mathrm{w} / \mathrm{v})$ sodium dodecyl sulfate were added and the solution was incubated at $80^{\circ} \mathrm{C}$ for 4 hours. After cooling to $40^{\circ} \mathrm{C}, 10 \mathrm{mg}$ of proteinase $\mathrm{K}$ was solved and the solution incubated for $24 \mathrm{~h}$ at $40^{\circ} \mathrm{C}$ under slight shaking. The proteinase $\mathrm{K}$ treatment was stopped by incubation at $80^{\circ} \mathrm{C}$ for 4 hours. The solution was diluted to $1 \mathrm{~L}$ with water, cleared by centrifugation with $13,000 \times \mathrm{g}$ for $1 \mathrm{~h}$ at $16^{\circ} \mathrm{C}$ and then processed as described above. The same procedure was applied for culture supernatant of S. rolfsii.

2.4. Immunization of Mice and Library Construction. Three mice (BALB/c, female, 7 weeks old) were immunized with $\mathrm{SCH}-\mathrm{PK}$ by intraperitoneal injection. Three injections were applied in two-week intervals. Each injection consisted of $25 \mu \mathrm{g}$ of SCH-PK and $50 \mu \mathrm{L}$ of the adjuvant Magic ${ }^{\mathrm{TM}}$ Mouse (Creative Biomart, New York, USA). Four weeks after the third injection, three additional injections with $50 \mu \mathrm{g}$ of
SCH-PK and $100 \mu \mathrm{L}$ of PBS (phosphate buffered saline) were applied over a period of three days to boost the $\mathrm{B}$ cell proliferation. Two days later, the mice were sacrificed. Their spleens were isolated and homogenized in TRIzol ${ }^{\circledR}$ LS Reagent (Life technologies, Carlsbad, USA).

A volume equal to $1 \times 10^{7}$ of homogenized leucocytes was used to isolate the RNA with the Direct-zol MiniPrep kit (Zymo Research, Irvine, USA). The isolation of the rearranged genes for the antibody domains $V_{L}$ (variable light) and $V_{H}$ (variable heavy) and their cloning into the phage display vector pHAL30 was carried out as described $[25,26]$. The derived $V_{L}$ sublibraries for lambda (V-LAMBDA) and kappa (V-KAPPA) of each mouse were kept separately. The six sublibraries were packaged with hyperphage [27].

2.5. Ethics Statement. The experimental protocols were carried out in accordance with the Directive 2010/63/EU of the European Parliament and the Council of the European Union of 22 September 2010 and all procedures were approved by guidelines from the Animal Committee on Ethics in the Care and Use of Laboratory Animals of TU Braunschweig, Germany (Az $\$ 5$ (02.05) TschB TU BS Az:33.42502-14005/08).

2.6. Immobilization of Schizophyllan onto Multiwell Plates. For the antibody selection and ELISA experiments, schizophyllan was immobilized to Carbo-BIND multiwell plates (Corning, Corning, USA). The wells were filled with $100 \mu \mathrm{L}$ of $10 \mu \mathrm{g} \mathrm{mL}^{-1} \mathrm{SCH}-\mathrm{PK}$ in $10 \mathrm{mmol} \mathrm{L}^{-1}$ acetate buffer $(\mathrm{pH} 5.4)$ and the sealed plates were incubated at $37^{\circ} \mathrm{C}$ overnight. The following day the wells were washed 10 times with water in an ELISA washer (HydroFlex ${ }^{\mathrm{TM}}$, Tecan, Männedorf, Switzerland) and filled for storage with $300 \mu \mathrm{L}$ PBS $\left(8.0 \mathrm{~g} \mathrm{~L}^{-1} \mathrm{NaCl}, 0.2 \mathrm{gL}^{-1} \mathrm{KCl}, 1.44 \mathrm{gL}^{-1}\right.$ $\mathrm{Na}_{2} \mathrm{HPO}_{3} * 4 \mathrm{H}_{2} \mathrm{O}, 0.24 \mathrm{~g} \mathrm{~L}^{-1} \mathrm{KH}_{2} \mathrm{PO}_{4}, \mathrm{pH}$ 7.4) containing $\mathrm{NaN}_{3}\left(0,2 \mathrm{~g} \mathrm{~L}^{-1}\right)$ until use.

2.7. Selection of Recombinant Antibodies against SCH by Antibody Phage Display. The rAbs were selected by panning as described [28] from the pooled immune libraries with VLAMBDA $\left(3 \times 10^{10}\right.$ colony forming units, cfu $)$ and V-KAPPA $\left(3 \times 10^{10} \mathrm{cfu}\right)$ which had been preincubated for $1 \mathrm{~h}$ in blank wells of a Carbo-BIND multiwell plate. Plasmid preparations (NucleoSpin ${ }^{\circledR}$ Plasmid EasyPure, Macherey-Nagel, Düren, Germany) were derived from the E. coli clones which contained a positive tested $\mathrm{rAB}$ and sent to Seqlab Sequence Laboratories $\mathrm{GmbH}$ (Göttingen, Germany) for sequencing. The sequences were compared with mouse germline sequences via the online sequence analysis tool IMGT/V-QUEST from the International ImMunoGeneTics information system ${ }^{\circledR}$ (IMGT ${ }^{\circledR}$, http://www.imgt.org/) $[29,30]$.

2.8. Production and Purification of Isolated Antibodies as $s c F v$ $F c$. For further characterization of the isolated rAbs, the DNA encoding the scFv (single chain Fragment variable) was subcloned into pCSE2.6-mIgG2c-Fc-XP via NcoI and NotI (New England Biolabs, Ipswich, USA). The resulting 
scFv-Fc fusions ( $\mathrm{scFv}$ fused with a murine Fc part) were produced in HEK239-6E cells (National Research Council, Biotechnological Research Institute, Montreal, Canada) as described [31]. Briefly, cells were cultivated in chemically defined medium FreeStyle ${ }^{\mathrm{TM}}$ F17 $\left(\mathrm{Gibco}^{\mathrm{TM}}\right.$, Thermo Fisher Scientific, Waltham, USA) added by $1 \mathrm{~g} \mathrm{~L}^{-1}$ Pluronic ${ }^{\circledR}$ F-68 (AppliChem, Darmstadt, Germany), $4 \mathrm{mmol} \mathrm{L}^{-1}$ glutamine (PAA Laboratories GmbH, Cölbe, Germany), and $25 \mathrm{mg} \mathrm{L}^{-1}$ G418 (PAA Laboratories $\mathrm{GmbH}$, Cölbe, Germany) at $37^{\circ} \mathrm{C}$, $110 \mathrm{rpm}$ as well as $5 \% \mathrm{CO}_{2}$ in the atmosphere (Minitron, Infors, Bottmingen, Switzerland). For transfection, $25 \mu \mathrm{g}$ of expression vector was used for $25 \mathrm{~mL}$ culture (about $1.5 \times$ $10^{6}$ cells $\mathrm{mL}^{-1}$ ) in a $125 \mathrm{~mL}$ Erlenmeyer shake flask. $48 \mathrm{~h}$ after transfection the culture was fed with $25 \mathrm{~mL}$ fresh media and $1.25 \mathrm{~mL}$ of $20 \%$ (w/v) tryptone N1 (Organotechnie S.A.S, La Courneuve, France). The secreted scFv-Fc was purified from the supernatant by affinity chromatography on a UNOsphere SUPrA $^{\mathrm{TM}}$ column (Biorad, Hercules, USA) and a Bio-Scale ${ }^{\mathrm{TM}}$ Mini Bio-Gel ${ }^{\circledR}$ P-6 Desalting cartridge (Biorad, Hercules, USA) in an automated Profinia ${ }^{\mathrm{TM}}$ system (BioRad, Hercules, USA). The concentrations of the preparations were calculated by their absorbance at $280 \mathrm{~nm}$ (NanoDrop 2000, Thermo Fisher Scientific, Waltham, USA).

2.9. Titration ELISA. The half-maximal effective concentration (EC50) values of the produced scFv-Fc were determined by titration ELISA (enzyme-linked immunosorbent assay) using serial dilutions of the $\mathrm{scFv}-\mathrm{Fc}$ in blocking solution (2\% (w/v) milk powder and 0.05\% (w/v) Tween ${ }^{\circledR} 20$ in PBS). ELISA was performed with SCH-PK loaded CarboBIND multiwell plates $\left(100 \mu \mathrm{L}_{\text {well }}{ }^{-1}, 10 \mu \mathrm{g} \mathrm{mL}^{-1}\right)$. The plate was blocked for $1 \mathrm{~h}$ at room temperature. The blocking solution was discarded and $100 \mu \mathrm{L}$ of the scFv-Fc (in blocking solution) was filled into the wells. After $1 \mathrm{~h}$ incubation, the plate was washed for 3 times with PBST (0.05\% (w/v) Tween 20 in PBS). Afterwards, $100 \mu \mathrm{L}_{\text {well }}{ }^{-1}$ peroxidase-conjugated goat anti-murine Fc antibody (A0168, 1: 40,000 in blocking solution) was added and incubated for an additional $1 \mathrm{~h}$. The plate was then washed again for 3 times with PBST. The color reaction was obtained by adding $100 \mu \mathrm{L}$ well ${ }^{-1}$ TMB solution $\left(20\right.$ volumes TMB A $\left(30 \mathrm{mmol} \mathrm{L}^{-1}\right.$ potassium citrate, $0.5 \mathrm{~mol} \mathrm{~L}^{-1}$ citric acid, $\mathrm{pH} 4.1$ ) and 1 volume TMB B $\left(10 \mathrm{mmol} \mathrm{L}^{-1} 3,3^{\prime}, 5,5^{\prime}\right.$-tetramethylbenzidine, $10 \%(\mathrm{v} / \mathrm{v})$ acetone, $90 \%(\mathrm{v} / \mathrm{v})$ ethanol, $\left.\left.0.3 \%(\mathrm{v} / \mathrm{v}) \mathrm{H}_{2} \mathrm{O}_{2}\right)\right)$. The reaction was stopped after $10 \mathrm{~min}$ by addition of $100 \mu \mathrm{L}$ well ${ }^{-1}$ of $0.5 \mathrm{~mol} \mathrm{~L}^{-1} \mathrm{H}_{2} \mathrm{SO}_{4}$. The resulting absorption was measured at $450 \mathrm{~nm}$ (reference wavelength $620 \mathrm{~nm}$ ).

2.10. Competitive ELISA. Antigen specificity was evaluated via competition of scFv-Fc binding to immobilized $\mathrm{SCH}-$ PK by various soluble saccharides. Each scFv-Fc was used in the concentration that resulted in $40 \%$ of the saturation signal in the titration ELISA. They were preincubated in serial dilutions of competitors $\left(3.2 \mathrm{ng} \mathrm{mL}^{-1}\right.$ to $1 \mathrm{mg} \mathrm{mL}^{-1}$, blocking solution as solvent) for $1 \mathrm{~h}$ before they were transferred to the SCH-PK loaded Carbo-BIND plate. The further procedure was done as described for titration ELISA. The following substances were used as competitors: SCH-PK, SCH, scleroglucan (S. rolfsii), cinerean, fructican, scleroglucan of Sclerotium glucanicum (DSM 2159), SCH from Contipro Biotech, Actigum CS 11 (scleroglucan), laminarin, dextran, xanthan, laminarihexaose (Megazyme, Wicklow, Ireland), beta-(1,6)D-gentiobiose, yeast extract (Ohly, Hamburg, Germany), and glucose. Furthermore, $\mathrm{NaOH}$ treated $\mathrm{SCH}-\mathrm{PK}$ was used, due to its changed secondary structure (triplex denatured to single chains, partial formation of cyclic structures). It was derived by adding $\mathrm{NaOH}$ until a $\mathrm{pH}$ of 13.8 had been reached and it was neutralized with $\mathrm{HCl}$ before use. Solutions of denatured SCH-PK and SCH were also used. Both were prepared by overnight incubation of SCH-PK and $\mathrm{SCH}$ with endoglucanase from Penicillium funiculosum (kindly provided by Erbslöh, Geisenheim, Germany) at $50^{\circ} \mathrm{C}$. The endoglucanase was inactivated by heating up to $80^{\circ} \mathrm{C}$ for 20 minutes.

All investigations were carried out at least in three independent experiments.

\section{Results and Discussion}

3.1. Selection and Identification of Recombinant Antibodies against Proteinase K Treated Schizophyllan. The goal of this study was the generation of a rAb that binds to the beta$(1,6)$-branched beta- $(1,3)$-D-glucan schizophyllan of Schizophyllum commune. We constructed a library from three immunized mice to increase the possibility of isolating the desired antibody. Since we wanted to derive an antibody which binds to the glucan itself, rather to possible residual protein contaminants, we used proteinase K treated SCH for immunization. The proteinase $\mathrm{K}$ treatment should eliminate proteins or other polypeptides that could be associated with the glucan. From each mouse, two sublibraries were derived, V-LAMBDA and V-KAPPA, which were pooled and used for the antibody selection on SCH-PK loaded CarboBIND multiwell plates. The surface of Carbo-BIND plates is functionalized with hydrazide-groups. Hydrazides react selectively with aldehyde groups under acidic conditions which allowed the covalent binding of the reducing end from SCH. Preliminary experiments showed that multiwell plates with other surface properties did not work and sometimes led to the generation of antibodies against adsorbed protein impurities (data not shown).

After three rounds of panning, 92 of the enriched antibody clones from each library were selected and the respective soluble $s c F v$-fragments were tested by ELISA for binding to SCH-PK. 60 clones of the V-KAPPA library showed specific binding; 10 of those clones with the highest signal and highest difference to the signal of the negative control were sequenced. Three individual antibodies (JoJ48C11, JoJ48F1, and JoJ49D10) with high sequence similarities were identified. The heavy chain of each recombinant antibody contains the variable gene IGHV1-7*01, the diversity gene IGHD1- $1 * 02$, and the joining gene IGHJ $2 * 01$. The variable gene of the light chain for each antibody is IGKV4-59*01. For the antibodies JoJ48C11 and JoJ49D10 the joining gene is IGKJ $5 * 01$. IGKJ $2 * 07$ was assigned to JoJ $48 \mathrm{~F} 1$. 


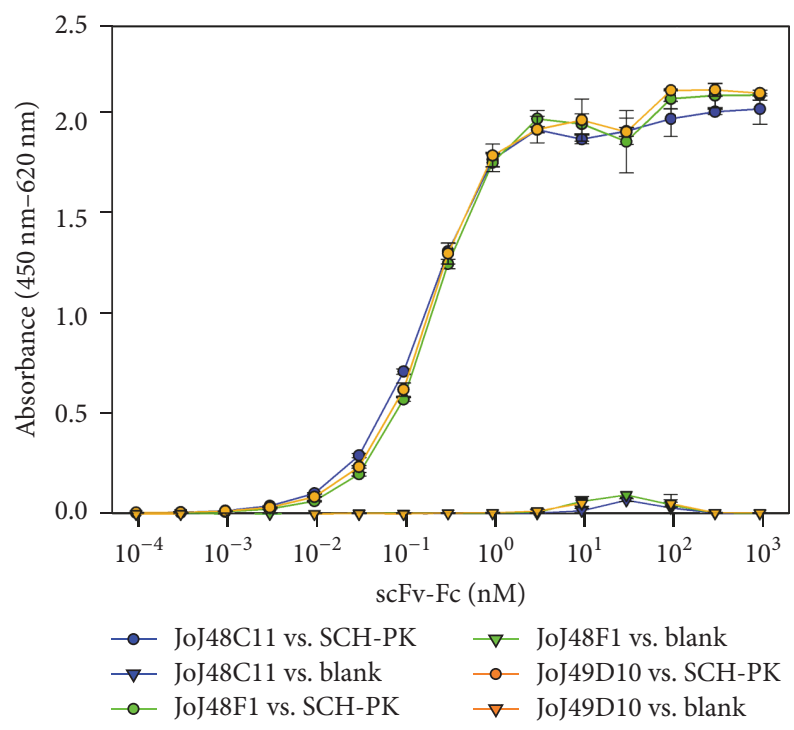

FIgure 1: Titration ELISA for analysis of the binding of the isolated antibodies in bivalent form $(\mathrm{scFv}-\mathrm{Fc})$. Dilution series of the antibodies from $0.095 \mathrm{pM}$ to $945 \mathrm{nM}$ were applied to SCH-PK coated or uncoated Carbo-BIND ${ }^{\mathrm{TM}}$ plates.

3.2. Binding Strength of the Isolated Antibodies as $s c F v-F c$. The three isolated $\mathrm{rAb}$ were produced as $\mathrm{scFv}-\mathrm{Fc}$ consisting of the $\mathrm{scFv}$ fused to a murine IgG2c Fc part. The $s c F v-F c$ format is a bivalent antibody comparable to a full length IgG [31].

The rAbs were analyzed as scFv-Fc by titration ELISA. Serial dilutions from $0.095 \mathrm{pM}$ to $945 \mathrm{nM}$ antibody were applied on SCH-PK loaded and blank Carbo-BIND multiwell plates. The resulting data (Figure 1) showed almost identical sigmoidal increase of the absorbance signal with increasing scFv-Fc concentration in a half-logarithm plot for all three antibodies. The half-maximal effective concentration (EC50) was derived from a regression of absorbance signal against the logarithm of antibody concentration by a sigmoidal function (3 parameters). The EC50 correlates with the affinity of the rAbs to SCH-PK [32]. The EC50 values are $155 \pm 4$ pM, 201 $\pm 7 \mathrm{pM}$ and $189 \pm 9 \mathrm{pM}$ for JoJ48C11, JoJ48F1, and JoJ49D10, respectively.

3.3. Antibody Specificity. Analysis for the specificity in antigen recognition was performed by a competitive approach. The rAbs were incubated in solutions of different saccharides or yeast extract before they were added to SCH-PK loaded Carbo-BIND plates. For illustration, only the data of JoJ49D10 are presented in Figure 2 because the results of JoJ48C11 and JoJ48F1 were very similar.

The expected decrease of signal with increasing concentrations of SCH-PK in solution was observed for each $\mathrm{rAb}$. Furthermore, a decrease of signal was also found, as expected, for nontreated SCH and the other beta- $(1,6)$-branched beta(1,3)-D-glucans like scleroglucan of $S$. rolfsii, cinerean, fructican, scleroglucan of $S$. glucanicum, proteinase $\mathrm{K}$ treated scleroglucan, SCH (Contipro Biotech), and Actigum CS 11 (scleroglucan from Degussa Construction Polymers). The scleroglucans and cinerean have a high similarity to $\mathrm{SCH}$.
They possess the same primary molecular structure, consisting of beta- $(1,6)$-linked D-glucose at every third glucose of the beta-(1,3)-D-glucan main chain. Additionally, they form also a triple helix as secondary structure [22, 23]. Fructican has a slightly different primary structure with beta$(1,6)$-bound D-glucose alternating at every second or third glucose of the main chain $[18,24]$. Its secondary structure is considered to be a triplex as well. The recognition of those glucans reveals a specificity of the rAbs not just for $\mathrm{SCH}$ but also for other high molecular beta-(1,6)-branched beta- $(1,3)$ D-glucans forming a triple helix.

Only a slight signal decrease at higher concentrations of $\mathrm{NaOH}$ treated SCH-PK was observed for each $\mathrm{rAb}$. Due to the $\mathrm{NaOH}$ treatment of SCH-PK, the glucan possesses a changed macromolecular structure. The triple helix denatures into single chains when the $\mathrm{pH}$ exceeds 13 [21]. Neutralization of those $\mathrm{SCH}$ solutions leads to minimal renaturation to the triple helical structure, while random coiled structures are primarily formed [33]. This observation indicates that the native triple helical structure is an important factor for the recognition of the beta-(1,6)-branched beta-(1,3)-Dglucan molecule by the selected antibodies, since the primary structure is not changed. The residual interaction could be explained by occasional formation of triple helical stretches inside the random coils and small amounts of renatured $\mathrm{SCH}$ triplex [34].

JoJ48C11 and JoJ48F1 showed a slight interaction with laminarin of Laminaria digitata. It consists of a beta-(1,3)D-glucan main chain with an occasional beta-(1,6)-bound D-glucose and exists predominantly as linear molecule with only approximately 5\% occurring as triplex [35]. This observation further corroborates the assumption that the triple helical structure is a key factor for $\mathrm{rAb}$ recognition.

Xanthan, dextran, laminarihexaose, beta-(1,6)-Dgentiobiose, glucose, yeast extract, and glucanase treated $\mathrm{SCH} / \mathrm{SCH}-\mathrm{PK}$ did not inhibit the binding of any of the three antibodies to SCH-PK. Xanthan consists of a beta-(1,4)-D-glucan backbone with beta-(1,3)-linked beta-D-mannose-(1,4)-beta-D-glucuronic acid-(1,2)-alphaD-mannose side chain at every second glucose and forms a double helix in aqueous solution [36]. Dextran is an alpha-(1,6)-D-glucan with around 5\% branching points at alpha-(1,3)-position to a single glucose or a dimer of glucose [37]. The results with xanthan and dextran indicate that there are no unspecific interactions of the rAbs with high molecular polysaccharides of different glycosidic linkages. D-glucose and laminarihexaose (linear hexamer of beta(1,3)-bound D-glucose) and beta-(1,6)-D-gentiobiose (dimer of beta-(1,6) bound D-glucose) also did not interfere with the binding of the rAbs to $\mathrm{SCH}$, indicating that D-glucose and the beta- $(1,6)$ or beta- $(1,3)$ linkage of D-glucose alone are not sufficient to provide binding by the rAbs. Yeast extract was the complex ingredient of the medium for the production of $\mathrm{SCH}$. The test assured that the antibodies do not bind to a residual impurity from the media in the used $\mathrm{SCH}$ solution. Incubation of $\mathrm{SCH}$ with endoglucanase degrades it into D-glucose monomers and oligomers. An interference of the glucanase treated solutions was not observed and indicated that degraded saccharides or other released components, 


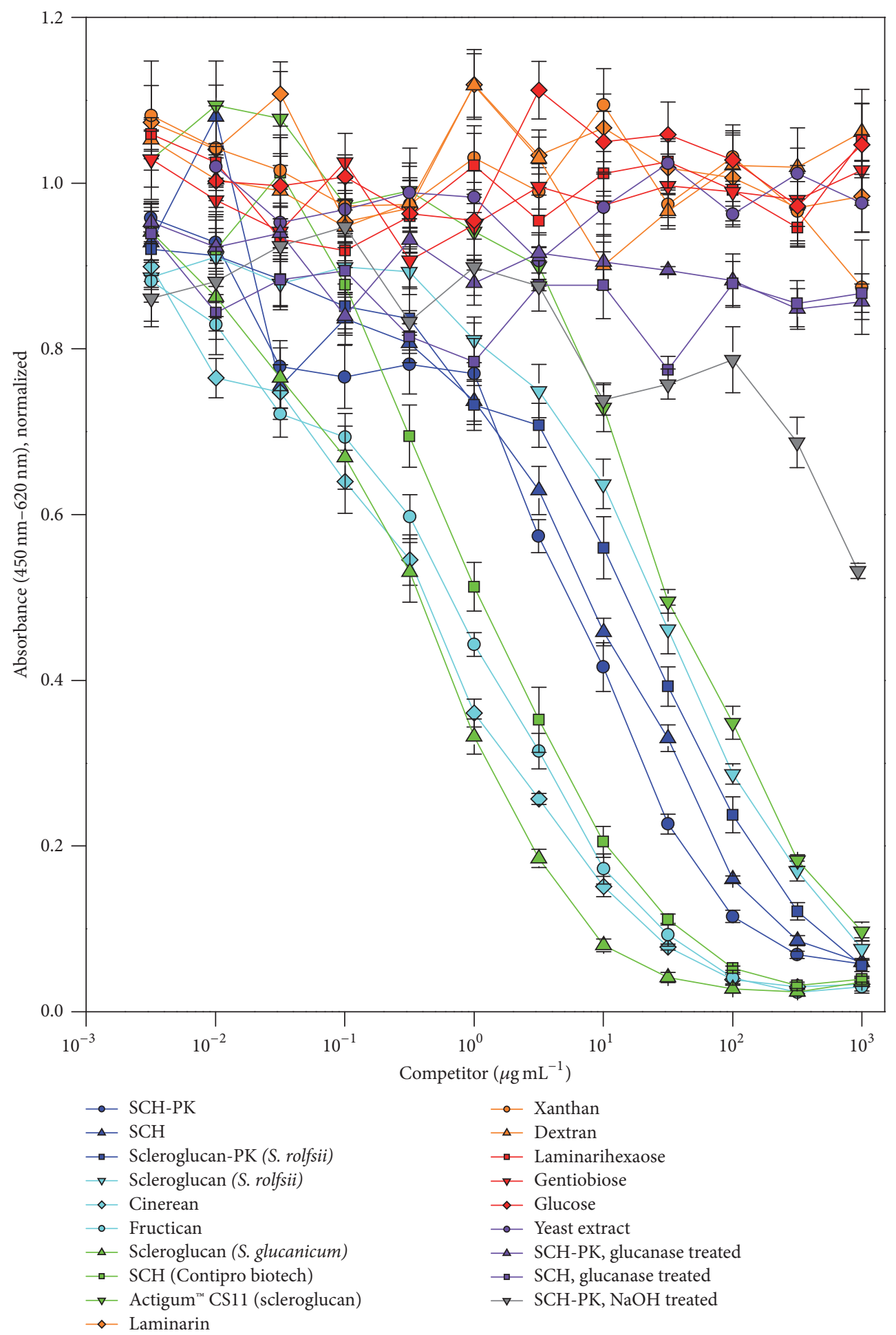

FIGURE 2: Competitive ELISA of antibody JoJ49D10 for the characterization of antigen specificity. JoJ49D10 (scFv-Fc) was preincubated in dilutions of different carbohydrates or yeast extract ranging from $10 \mathrm{ng} \mathrm{mL}^{-1}$ to $1 \mathrm{mg} \mathrm{mL}^{-1}$ before being added to SCH-PK loaded Carbo-BIND multiwell plates. The absorbance signals were normalized by division with the absorbance of respective samples without competitor.

including potential protein impurities, were not recognized by the antibodies.

The experiments showed that the triple helical structure of the glucans is the essential factor for antibody recognition.
It is assumed that the spatial arrangement of the beta$(1,6)$-linked D-glucose residues is an important part of the antibody binding epitope. The beta-(1,6)-branching ratio of the glucan also affects the reactivity of the antibody binding. 
TABLE 1: EC50 values of competitors which are recognized by the recombinant antibodies.

\begin{tabular}{|c|c|c|c|}
\hline \multirow{2}{*}{ Competitors } & \multicolumn{3}{|c|}{ EC50 values $\left[\mu \mathrm{g} \mathrm{mL}^{-1}\right]$} \\
\hline & JoJ48C11 & JoJ48F1 & JoJ49D10 \\
\hline SCH-PK & $25.1 \pm 1.8$ & $24.9 \pm 3.7$ & $7.8 \pm 1.0$ \\
\hline $\mathrm{SCH}$ & $36.2 \pm 4.6$ & $29.4 \pm 6.4$ & $9.1 \pm 0.6$ \\
\hline Scleroglucan (S. rolfsii) & $54.4 \pm 2.0$ & $52.3 \pm 5.3$ & $19.9 \pm 2.8$ \\
\hline Scleroglucan (PK-treated) & $83.1 \pm 5.1$ & $54.5 \pm 13.2$ & $34.0 \pm 1.2$ \\
\hline Cinerean & $4.2 \pm 0.2$ & $4.7 \pm 0.7$ & $0.5 \pm 0.1$ \\
\hline Fructican & $6.8 \pm 0.4$ & $8.8 \pm 1.8$ & $1.0 \pm 0.2$ \\
\hline Scleroglucan (S. glucanicum) & $3.1 \pm 0.2$ & $1.7 \pm 0.5$ & $0.4 \pm 0.1$ \\
\hline SCH (Contipro biotech) & $8.2 \pm 1.2$ & $7.0 \pm 1.2$ & $1.1 \pm 0.2$ \\
\hline Actigum CS11 (Scleroglucan) & $88.5 \pm 5.0$ & $74.2 \pm 14.4$ & $31.7 \pm 1.5$ \\
\hline
\end{tabular}

Fructican possesses a higher degree of branching points but does not influence the reactivity of the antibodies compared to the different types of schizophyllan and scleroglucan as well as cinerean. Laminarin shows not only a low occurrence of triplex structure but also a lower degree of branching which could be also responsible for the weak antibody binding. This leads to the additional conclusion that besides the triplex the beta-(1,6)-branching degree also influences antibody reactivity.

With the gained datasets the EC50 values of the competing glucans (except for $\mathrm{NaOH}$ treated SCH-PK and laminarin) were calculated from the signal reduction and compared as value for the binding strength of the antibodies to the glucans (all data shown in Table 1). In dependence of the $\mathrm{rAb}$, the EC50 values for SCH-PK varied between 7.8 to $25.1 \mu \mathrm{g} \mathrm{mL}^{-1}$. The proteinase $\mathrm{K}$ untreated SCH offered jointly increased EC50 of 9.1 to $36.2 \mu \mathrm{g} \mathrm{mL}^{-1}$. The lowest EC50 values of 0.4 to $3.1 \mu \mathrm{g} \mathrm{mL}^{-1}$ and consequently the greatest interference were observed for scleroglucan from S. glucanicum. The difference of EC50 values between the glucans can be explained by different molecular size distribution, occurrence of additional macromolecular structures depending on the production strains, and downstream processing. For example, SCH and SCH-PK showed similar EC50 values because both derived from the same production batch and were identically purified except proteinase $\mathrm{K}$ treatment. The commercial SCH purchased by Contipro Biotech, produced and purified in unknown procedures, showed lower EC50 data.

In summary, the results suggest that the generated rAbs recognize a conformational epitope requiring an intact triple helical secondary structure of beta-(1,6)-branched beta-(1,3)D-glucans with an optimal branching degree of one beta$(1,6)$-bound D-glucose attached to approximately every three glucose units of the main chain. As a consequence, the rAbs not only are specific for SCH but also bind to similar beta-(1,6)-branched beta-(1,3)-D-glucans with triple helical structure.

Reports about the generation of an antibody against $\mathrm{SCH}$ already exist. Tabata et al. reported the generation of an antiserum from immunized rabbits [38]. Other authors described the isolation of a monoclonal antibody against $\mathrm{SCH}$ from immunized mice via hybridoma technology [39].
That antibody was also able to bind other beta-(1,6)-branched beta-(1,3)-D-glucans like scleroglucan and even bound to laminaritetraose, a tetramer of beta-(1,3)-bound D-glucose.

Investigations of monoclonal antibodies generated with other beta-(1,3)-D-glucans also exist with binding specificities to more than one glucan [40-43]. Just recently, two antibodies against the extracellular beta-glucan of Pleurotus ostreatus were isolated $[44,45]$. This glucan exhibits the same molecular structure as SCH. It is assumed as well that these antibodies recognize and bind to a common conformational epitope. The difference to our investigations is that we proved the triple helical arrangement as an essential element for the recognition by the rAbs. Furthermore, it was verified by proteinase and endoglucanase treatment that the rAbs bind to the sugar structure and not to associated proteins or peptides.

\section{Conclusion}

In this report the successful generation of three recombinant glucan antibodies is described. They were selected for binding to the beta-(1,6)-branched beta-(1,3)-D-glucan schizophyllan of Schizophyllum commune from an immune library via phage display. In addition to schizophyllan, the antibodies recognize other beta-(1,6)-branched beta-(1,3)-D-glucans that possess a triplex as secondary structure and similar branching degree as schizophyllan. As other helical arrangements and lower order oligomers or monomers were not bound, the antigenic epitope is assumed to be conformational. Therefore, the antibodies can be used as analytical tools for the specific detection of schizophyllan and similar beta-(1,6)-branched beta-(1,3)-D-glucans with triple helical arrangement.

\section{Conflicts of Interest}

The authors declare that there are no conflicts of interest regarding the publication of this paper.

\section{Acknowledgments}

The authors would like to thank Doris Meier and Wolfgang Graßl for their technical assistance. The authors appreciate the support and help of Michael Hust in antibody selection, data analysis, and writing of the manuscript. 


\section{References}

[1] X. Meng, H. Liang, and L. Luo, "Antitumor polysaccharides from mushrooms: a review on the structural characteristics, antitumor mechanisms and immunomodulating activities," Carbohydrate Research, vol. 424, pp. 30-41, 2016.

[2] N. Komatsu, S. Okubo, S. Kikumoto, K. Kimura, G. Saito, and S. Sakai, "Host-mediated antitumor action of schizophyllan, a glucan produced by Schizophyllum commune," Japanese Journal of Cancer Research, vol. 60, no. 2, pp. 137-144, 1969.

[3] A. Mansour, A. Daba, N. Baddour, M. El-Saadani, and E. Aleem, "Schizophyllan inhibits the development of mammary and hepatic carcinomas induced by 7,12 dimethylbenz $(\alpha)$ anthracene and decreases cell proliferation: comparison with tamoxifen," Journal of Cancer Research and Clinical Oncology, vol. 138, no. 9, pp. 1579-1596, 2012.

[4] U. Rau, "Schizophyllan," in Biotechnology of Biopolymers. From Synthesis to Patents, A. Steinbüchel and Y. Doi, Eds., vol. 1, pp. 703-735, Wiley-VCH Verlag GmbH \& Co. KGaA, Weinheim, Baden-Württemberg, Germany, 2005.

[5] Y. Shimizu, J. T. Chen, Y. Hirai et al., "Augmentation of immune responses of pelvic lymph node lymphocytes in patients with cervical cancer by sizofiran," Nihon Sanka Fujinka Gakkai zasshi, vol. 41, no. 12, pp. 2013-2014, 1989.

[6] V. E. C. Ooi and F. Liu, "Immunomodulation and anti-cancer activity of polysaccharide-protein complexes," Current Medicinal Chemistry, vol. 7, no. 7, pp. 715-729, 2000.

[7] M. Suzuki, T. Arika, K. Amemiya, and M. Fujiwara, "Cooperative role of $\mathrm{T}$ lymphocytes and macrophages in anti-tumor activity of mice pretreated with schizophyllan (SPG)," Japanese Journal of Experimental Medicine, vol. 52, no. 2, pp. 59-65, 1982.

[8] I. Sugawara, K. C. Lee, and M. Wong, "Schizophyllan (SPG)treated macrophages and anti-tumor activities against syngeneic and allogeneic tumor cells-I. Characteristics of SPGtreated macrophages," Cancer Immunology Immunotherapy, vol. 16, no. 3, pp. 137-144, 1984.

[9] Y. Tsuchiya, M. Igarashi, K. Kumagai, and M. Inoue, "Cytokinerelated immunomodulating activities of an anti-tumor glucan, sizofiran (SPG)," Journal of Pharmacobio-Dynamics, vol. 12, no. 10, pp. 616-625, 1989.

[10] S. Kikumoto, Tt. Miyajima, S. Yoshizumi, S. Fujimoto, and K. Kimura, "Polysaccharide produced by Schizophyllum commune. Part I. Formation and some properties of an extracellular polysaccharide," Journal of the Agricultural Chemical Society of Japan, vol. 44, pp. 337-342, 1970.

[11] S. Kikumoto, T. Miyajima, K. Kimura, S. Okubo, and N. Komatsu, "Polysaccharide produced by schizophyllum commune. Part II. Chemical structure of an extracellular polysaccharide," Journal of the Agricultural Chemical Society of Japan, vol. 45, pp. 162-168, 1971.

[12] T. Norisuye, T. Yanaki, and H. Fujita, "Triple helix of a schizophyllum commune polysaccharide in aqueous solution," Journal of Polymer Science. Part A-2, Polymer physics, vol. 18, no. 3, pp. 547-558, 1980.

[13] T. Sato, T. Norisuye, and H. Fujita, "Triple helix of Schizophyllum commune polysaccharide in dilute solution. 5. Light scattering and refractometry in mixtures of water and dimethyl sulfoxide," Macromolecules, vol. 16, no. 2, pp. 185-189, 1983.

[14] T. Yanaki, T. Norisuye, and H. Fujita, "Triple helix of Schizophyllum commune polysaccharide in dilute solution. 3. Hydrodynamic properties in water," Macromolecules, vol. 13, no. 6, pp. 1462-1466, 1980.
[15] Y. Kashiwagi, T. Norisuye, and H. Fujita, "Triple helix of Schizophyllum commune polysaccharide in dilute solution. 4. Light scattering and viscosity in dilute aqueous sodium hydroxide," Macromolecules, vol. 14, no. 5, pp. 1220-1225, 1981.

[16] T. Kojima, K. Tabata, W. Itoh, and T. Yanaki, "Molecular weight dependence of the antitumor activity of schizophyllan," Agricultural and Biological Chemistry, vol. 50, no. 1, pp. 231-232, 1986.

[17] S. Kitamura, T. Hori, K. Kurita et al., "An antitumor, branched $(1 \rightarrow 3)-\beta$-D glucan from a water extract of fruiting bodies of Cryptoporus volvatus," Carbohydrate Research, vol. 263, no. 1, pp. 111-121, 1994.

[18] W.-M. Kulicke, A. I. Lettau, and H. Thielking, "Correlation between immunological activity, molar mass, and molecular structure of different $(1 \rightarrow 3)$ - $\beta$-D-glucans," Carbohydrate Research, vol. 297, no. 2, pp. 135-143, 1997.

[19] U. Rau and F. Wagner, "Non-newtonian flow behaviour of colloid-disperse glucan solutions," Biotechnology Letters, vol. 9, no. 2, pp. 95-100, 1987.

[20] T. Yanaki, K. Tabata, and T. Kojima, "Melting behaviour of a triple helical polysaccharide schizophyllan in aqueous solution," Carbohydrate Polymers, vol. 5, no. 4, pp. 275-283, 1985.

[21] H. Saitô, T. Ohki, and T. Sasaki, "A 13C-nuclear magnetic resonance study of polysaccharide gels. Molecular architecture in the gels consisting of fungal, branched $(1 \rightarrow 3)-\beta$-D glucans (lentinan and schizophyllan) as manifested by conformational changes induced by sodium hydroxide," Carbohydrate Research, vol. 74, no. 1, pp. 227-240, 1979.

[22] T. L. Bluhm, Y. Deslandes, R. H. Marchessault, S. Pérez, and M. Rinaudo, "Solid-state and solution conformation of scleroglucan," Carbohydrate Research, vol. 100, no. 1, pp. 117-130, 1982.

[23] M. Gawronski, N. Donkai, T. Fukuda, T. Miyamoto, H. Conrad, and T. Springer, "Triple helix of the polysaccharide cinerean in aqueous solution," Macromolecules, vol. 30, pp. 6994-6996, 1997.

[24] F. Santamaria, F. Reyes, and R. Lahoz, "Extracellular glucan containing $(1 \rightarrow 3)-\beta$ and $(1 \rightarrow 6)-\beta$ linkages isolated from Monilinia fructigena," Journal of General Microbiology, vol. 109, no. 2, pp. 287-293, 1978.

[25] L. Toleikis and A. Frenzel, "Cloning single-chain antibody fragments ( $\mathrm{ScFv}$ ) from hyrbidoma cells," Methods in Molecular Biology, vol. 907, pp. 59-71, 2012.

[26] J. Kügler, S. Wilke, D. Meier et al., "Generation and analysis of the improved human HAL9/10 antibody phage display libraries," BMC Biotechnology, vol. 15, no. article 10, 2015.

[27] S. Rondot, J. Koch, F. Breitling, and S. Dübel, "A helper phage to improve single-chain antibody presentation in phage display," Nature Biotechnology, vol. 19, no. 1, pp. 75-78, 2001.

[28] A. Frenzel, J. Kügler, S. Wilke, T. Schirrmann, and M. Hust, "Construction of human antibody gene libraries and selection of antibodies by phage display," Human Monoclonal Antibodies: Methods and Protocols, pp. 215-243, 2014.

[29] V. Giudicelli, X. Brochet, and M.-P. Lefranc, "IMGT/V-QUEST: IMGT standardized analysis of the immunoglobulin (IG) and T cell receptor (TR) nucleotide sequences," Cold Spring Harbor Protocols, vol. 6, no. 6, pp. 695-715, 2011.

[30] X. Brochet, M.-P. Lefranc, and V. Giudicelli, "IMGT/V-QUEST: the highly customized and integrated system for IG and TR standardized V-J and V-D-J sequence analysis," Nucleic acids research, vol. 36, pp. W503-W508, 2008. 
[31] V. Jäger, K. Büssow, A. Wagner et al., "High level transient production of recombinant antibodies and antibody fusion proteins in HEK293 cells," BMC Biotechnology, vol. 13, article 52, 2013.

[32] V. Van Heyningen, D. J. H. Brock, and S. Van Heyningen, "A simple method for ranking the affinities of monoclonal antibodies," Journal of Immunological Methods, vol. 62, no. 2, pp. 147-153, 1983.

[33] M. Sletmoen, E. Geissler, and B. T. Stokke, "Determination of molecular parameters of linear and circular scleroglucan coexisting in ternary mixtures using light scattering," Biomacromolecules, vol. 7, no. 3, pp. 858-865, 2006.

[34] B. T. Stokke, A. Elgsaeter, D. A. Brant, T. Kuge, and S. Kitamura, "Macromolecular cyclization of $(1 \rightarrow 6)$-branched$(1 \rightarrow 3)$ - $\beta$-D-glucans observed after denaturation-renaturation of the triple-helical structure," Biopolymers, vol. 33, no. 1, pp. 193-198, 1993.

[35] M. Oda, Y. Tanabe, M. Noda et al., "Structural and binding properties of laminarin revealed by analytical ultracentrifugation and calorimetric analyses," Carbohydrate Research, vol. 431, pp. 33-38, 2016.

[36] K. Born, V. Langendorff, and P. Boulenguer, "Xanthan," in Biopolymers, E. Vandamme, S. De Baets, and A. Steinbüchel, Eds., vol. 5, pp. 259-291, Wiley-VCH Verlag GmbH \& Co. KGaA, Weinheim, Baden-Württemberg, Germany, 2002.

[37] O. Larm, B. Lindberg, and S. Svensson, "Studies on the length of the side chains of the dextran elaborated by Leuconostoc mesenteroides NRRL B-512," Carbohydrate Research, vol. 20, no. 1, pp. 39-48, 1971.

[38] K. Tabata, W. Itoh, A. Hirata, I. Sugawara, and S. Mori, "Preparation of polyclonal antibodies to an anti-tumor $(1 \rightarrow 3)-\beta-\mathrm{D}$ glucan, schizophyllan," Agricultural and Biological Chemistry, vol. 54, no. 8, pp. 1953-1959, 1990.

[39] A. Hirata, W. Itoh, K. Tabata, T. Kojima, S. Itoyama, and I. Sugawara, "Preparation and characterization of murine anti-schizophyllan monoclonal antibody, SPG1-HS," Bioscience, Biotechnology and Biochemistry, vol. 57, no. 1, pp. 125-126, 1993.

[40] A. Hirata, Y. Adachi, W. Itoh, M. Komoda, K. Tabata, and I. Sugawara, "Monoclonal antibody to proteoglycan derived from Grifola frondosa (Maitake)," Biological and Pharmaceutical Bulletin, vol. 17, no. 4, pp. 539-542, 1994.

[41] J. Douwes, G. Doekes, R. Montijn, D. Heederik, and B. Brunekreef, "An immunoassay for the measurement of $(1 \rightarrow 3)$ $\beta$-D-glucans in the indoor environment," Mediators of Inflammation, vol. 6, no. 4, pp. 257-262, 1997.

[42] A. Torosantucci, P. Chiani, C. Bromuro et al., "Protection by anti- $\beta$-glucan antibodies is associated with restricted $\beta-1,3$ glucan binding specificity and inhibition of fungal growth and adherence," PLoS ONE, vol. 4, no. 4, Article ID e5392, 2009.

[43] I. Sander, C. Fleischer, G. Borowitzki, T. Brüning, and M. RaulfHeimsoth, "Development of a two-site enzyme immunoassay based on monoclonal antibodies to measure airborne exposure to $(1 \rightarrow 3)$ - $\beta$-d-glucan," Journal of Immunological Methods, vol. 337 , no. 1, pp. 55-62, 2008.

[44] M. C. Semedo, A. Karmali, S. Martins, and L. Fonseca, "Generation of high-affinity monoclonal antibodies of IgG class against native $\beta$-D glucans from basidiomycete mushrooms," Process Biochemistry, vol. 51, no. 2, pp. 333-342, 2016.

[45] M. C. Semedo, A. Karmali, S. Martins, and L. Fonseca, "Novel polyol-responsive monoclonal antibodies against extracellular $\beta$-D glucans from Pleurotus ostreatus," Biotechnology Progress, vol. 32, no. 1, pp. 116-125, 2016. 

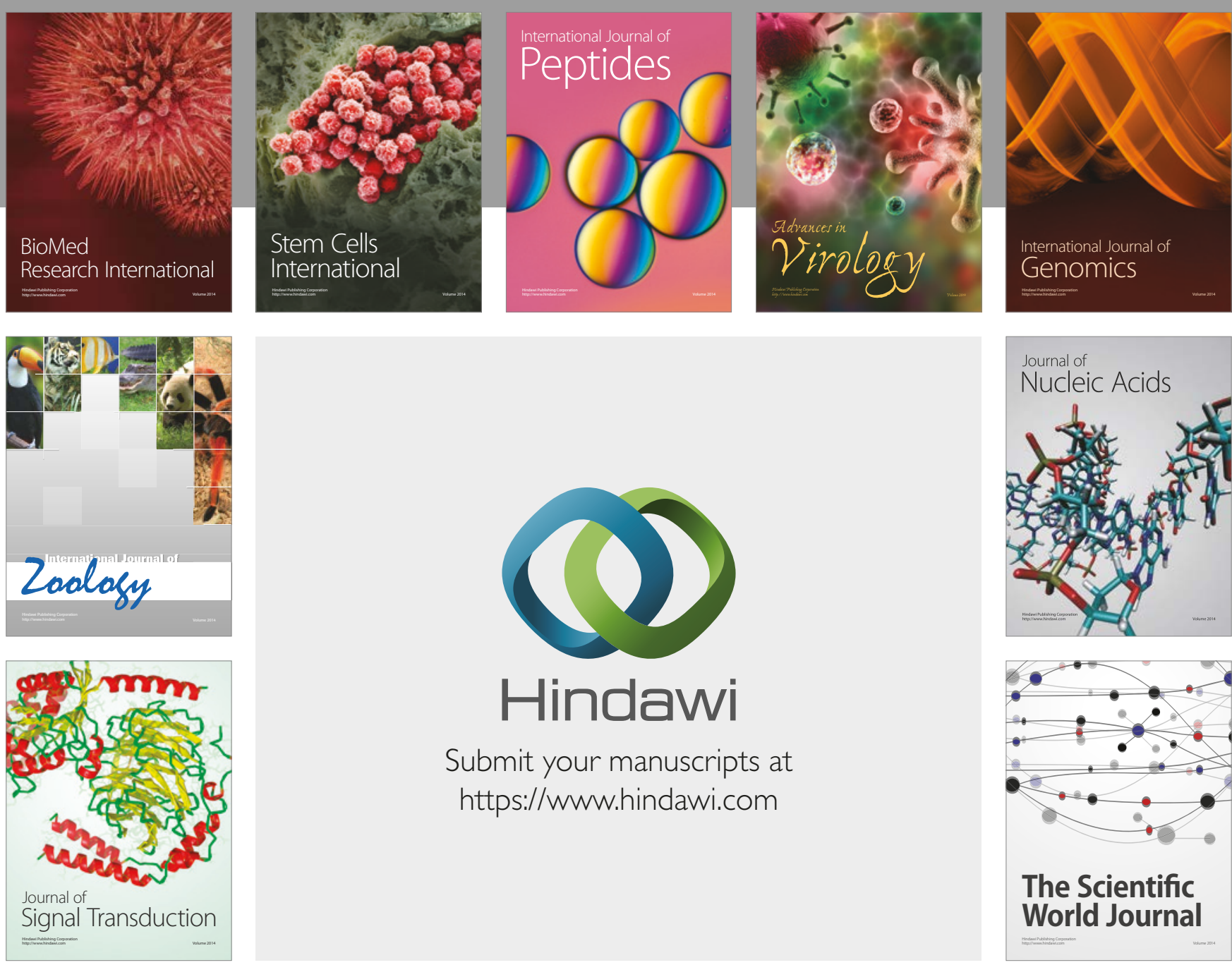

Submit your manuscripts at

https://www.hindawi.com
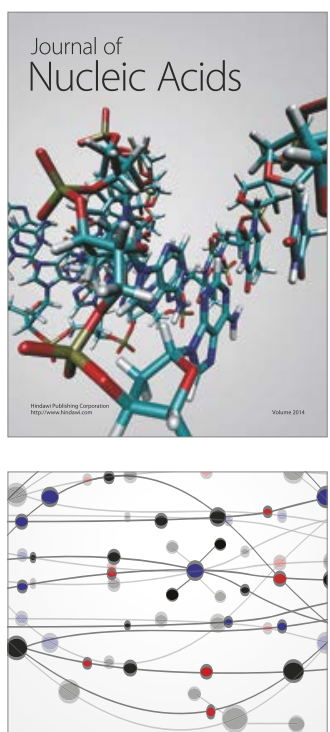

The Scientific World Journal

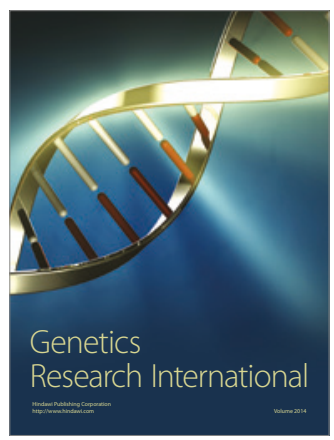

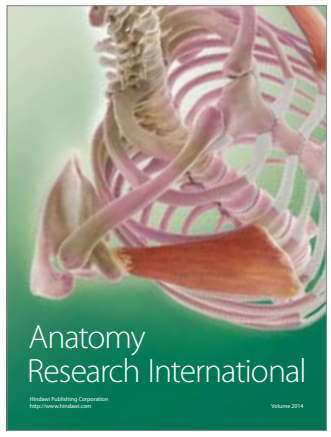

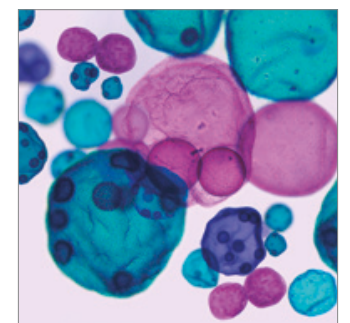

International Journal of Microbiology
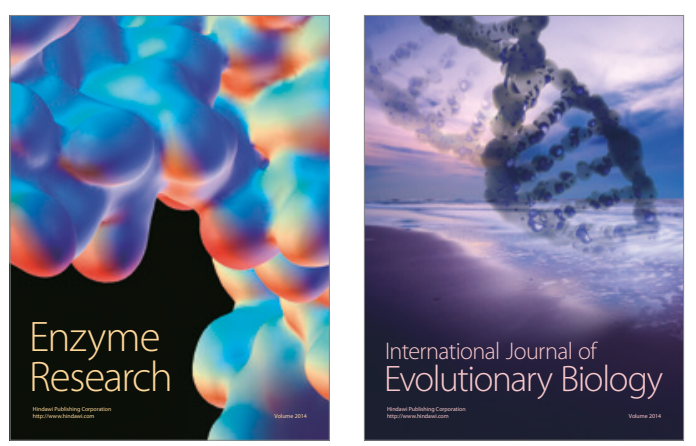
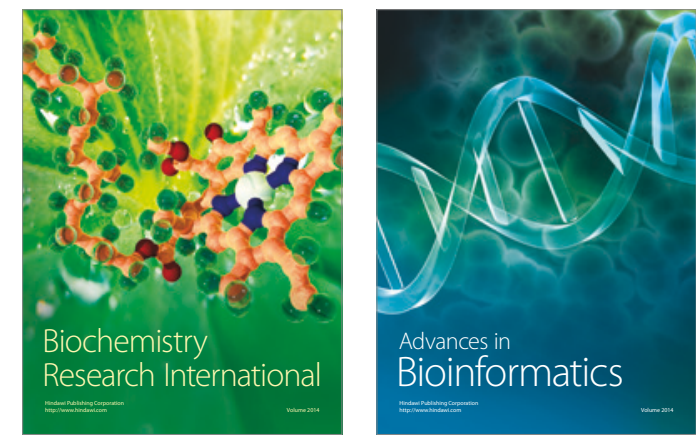

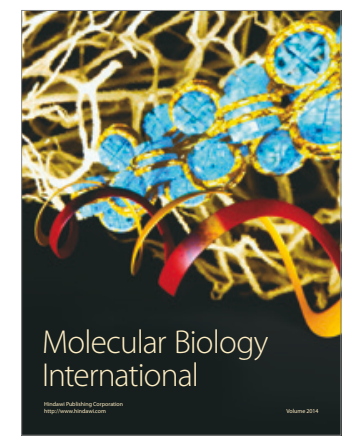

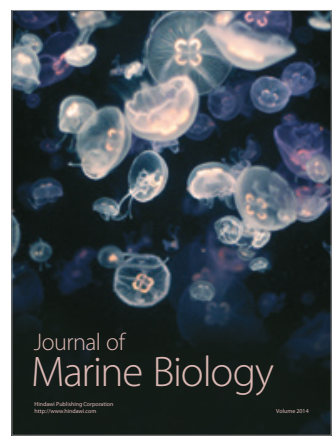

